\title{
Unconditional Self-Acceptance and Perfectionistic Cognitions as Predictors of Psychological Well-Being
}

\author{
Tuğba Yılmaz Bingöl ${ }^{1}$, Meryem Vural Batık ${ }^{2}$ \\ ${ }^{1}$ Fatih Sultan Mehmet Vakıf University, Faculty of Education, Psychological Counselor and Guidance, Turkey \\ ${ }^{2}$ Ondokuz Mayıs University, Faculty of Education, Special Education,Turkey \\ Correspondence: Tuğba Yılmaz Bingöl, Fatih Sultan Mehmet Vakıf University, Faculty of Education, Psychological \\ Counselor and Guidance, Turkey.
}

Received: October 25, 2018

Accepted: December 2, 2018 Online Published: December 12, 2018

doi:10.11114/jets.v7i1.3712

URL: https://doi.org/10.11114/jets.v7i1.3712

\begin{abstract}
Psychological well-being which is an important concept for individual mental health involves maintaining meaningful aims in life, developing quality relationships with others and struggling with life to ensure personal development. Based on the importance of the concept of psychological well-being, in this study, it is aimed to determine the predictors of psychological well-being of prospective teachers who are expected to make a contribution in the healthy development of students. A total of 378 prospective teachers have participated to the study which was conducted according to the general screening model. Path analysis was used in the analysis of the data to test the predictive roles of unconditional self-acceptance, perfectionistic cognitions and perceived income levels of prospective teachers on their psychological well-being level. Results indicated that psychological well-being has a positive significance but low correlation with unconditional self-acceptance and perfectionistic cognitions. In addition, it was found that of unconditional self-acceptance, perfectionistic cognitions and perceived income level accounted for $16 \%$ of the total variance of psychological well-being. It was also determined that female participants' psychological well-being scores were higher than males' and psychological well-being levels of participants who perceived their income level as good were higher than those perceived their income level as medium and low.
\end{abstract}

Keywords: unconditional self-acceptance, perfectionistic cognitions, psychological well-being, path analysis, prospective teacher, teacher education

\section{Introduction}

Psychological well-being can be defined as managing the existential challenges of life (e.g., pursuing meaningful goals, developing as a person and establishing quality relations with other people) (Keyes, Shmotkin, \& Ryff, 2002) and studies on psychological well-being have a long history which based on Bradburn's (1969) study that aimed to investigate the impact of the social changes such as level of education, employment, and urbanization on an individual's life situation as a citizen and on their psychological well-being.

Roothman, Kirsten and Wissing (2003) stated that psychological well-being can be conceptualized regarding emotional, physical, cognitive, spiritual, personal and social processes. Psychological well-being provides information about how one sees one's self and the characteristics of his life. Psychological well-being means having a beautiful life and doing significant things in life rather than perceive himself/herself as good (Ryff, Magee, Kling, \&Wing, 1999).

Keyes et al. (2002) have defined psychological well-being as having positive perceptions about himself or herself, having good feelings about himself or herself even aware of his/her own limitations, developing and maintaining warm and trustful social relationship, shaping the environment in a way to meet personal needs and wishes, acting or behaving autonomously without depending anyone else, attempting to find meaning in life and having purposes in life, being aware of the limits of personal potential and making effort to growth this potential and capabilities . Waterman (1993) stated that psychological well-being is making an effort against life in order to provide individual development. On the other hand, Akın (2009) claimed that using operational constructs would be more helpful to define the construct of psychological well-being rather than making a clear definition.

In his study, Ryff (1989a) examined whether the work of various theorists, such as Maslow, Rogers, Jung, Allport, 
Erikson, Buhler, Neugarten and Jahoda, was related to psychological well-being. As a result, he introduced the six-dimensional model of psychological well-being (Self-acceptance, positive relationships with others, autonomy, environmental mastery, purpose in life, and personal development).

Self-acceptance which is one of the dimensions of Ryff's psychological well-being model means having a positive attitude toward the self which includes good and bad qualities and having positive feelings about the past. Positive relations with others include having good and trusting relationships with others and feeling empathy, love, and trust. The concept of autonomy means regulating behaviors acting in a certain way by resisting social pressure. Environmental mastery reflects to manage the environment, have a sense of competence and mastery. The purpose in life is having goals in life and outlook that gives life meaning. Personal growth which is a close concept to self-actualization means having a sense of realizing potential (Ryff, 1989a). From this point of view, psychological well-being is a broad concept which is based on empirical theories.

Ryff (1989b) also have based the concept of psychological well-being on Aristotle's construct of 'eudemonia'. Ryff and Singer (2008) stated that in previous studies Aristotle's concept of eudemonia has been translated to mean happiness but this translation is inadequate to explain the concept of eudemonia. Besides, they remarked that eudemonia is the highest points of all goods reachable by human activity rather than happiness. In Ryff's (1995) theory, it is emphasized the importance of being aware of the individual potential and making this potential functional to reach self-fulfillment. In this sense empowerment of human is important. The characteristics that the power of the individual may bring along psychological well-being. Because psychological well-being requires the individual to develop his potential to be able to fully-functioning (Ryff, 1989a).

When the literature is examined, several studies on the relationship between psychological well-being and different variables such as social support (Lavasani, Borhanzadeh, Afzali, \& Hejazi, 2011; Shakespeare-Finch \& Green, 2013), life satisfaction, positive and negative emotions (Ryff, 1989a), family satisfaction (Mills, Grasmick, Morgan, \& Wenk, 1992), personality (Schmutte \& Ryff, 1997), early life experiences (Maier \& Lachman, 2000), low neuroticism, education level, age, conscientiousness and extraversion (Keyes et al. 2002), social support, physical health, negative affect (Kahn, Hessling, \& Russel, 2003), self-efficacy, optimism, social support (Karademas, 2006) and social skills (Segrin \& Taylor, 2007) have been conducted. Based on the study of Ryff (1989a), the present study aimed to examine the relationship between self-acceptance and perfectionism with psychological well-being.

Unconditional self-acceptance is a concept developed by Ellis (1977, p. 101) as a solution to the problems of individuals related to self-evaluation and self-esteem and can be defined as accepting oneself as a whole and in an unconditional way by acting competently and smartly and without concerning about others approval. Acceptance occurs when a person considers himself/herself and others as a fallible person. In addition, living conditions are accepted as they exist. Individuals whose self- acceptance is higher acknowledge that the world is complex and that events are often out of personal control. However, this does not mean that acceptance is giving up. This acceptance philosophy means acknowledging that all that exists exists but they do not have to exist forever (Dryden, David, \& Ellis, 2010).

Self-acceptance refers to the individual's satisfaction about himself/herself and is considered necessary for good mental health (Rogers, 1951; Scott, 1968). Self-acceptance requires a realistic and subjective awareness of one's own strengths and weaknesses. Self-acceptance causes the individual to feel that he/she is a 'unique value' (English \& English, 1958; Jersild, 1960).

Unconditional self-acceptance involves accepting self without concerning about others love, respect, and approval (Hill, Hall, Appleton, \& Kozub, 2008). An unconditional acceptance can be mentioned, even if the individual accepts himself/herself even when he/she is behaving in a wrong or unsuccessful manner. It is not necessary to evaluate or judge yourself or others as a whole positively or negatively. For example, a person's failure to complete a work does not make him an unsuccessful individual (Neean \& Dryden, 2005, p: 5). In such a case, an individual should say 'I performed a low performance' rather than saying 'I am unsuccessful' (Maclnnes, 2003).

The concept of perfectionistic cognitions can be defined as automatic thoughts that are related with an individual's internal dialogues considering the need for being perfect and seeing own mistakes or deficiencies and the need for being perfect (Hewitt \& Flett, 2002, 2007). Individuals who use perfectionistic cognitions frequently tend to exhibit A-type behaviors and self-punishing attitudes and perfectionistic cognitions are found positively correlated with the obsession of failure and self-criticism (Flett, Hewitt, Blankstein, \& Gray 1998).

It is known that perfectionistic cognitions are related to concepts such as high stress and anxiety level (Flett, Madorsky, Hewitt, \& Heisel, 2002) and depression (Besser, Flett, \&Hewitt, 2010). However, Stoeber and Otto (2006) found that perfectionistic strivings, a healthy and adaptive dimension of perfectionism, are highly associated with extraversion, conscientiousness, endurance, positive affect, life satisfaction, active coping styles, exam performance, and external locus of control, low level of suicidal ideation, high level of perceived social support, depression and low level of self-blame. 
The psychological health of the teachers who are responsible to raise the next healthy generation is of course important. For this reason and based on the studies given above the main problem of the present study is as follow:

Do the prospective teachers' unconditional self-acceptance, perfectionistic cognitions and perceived income levels predict their psychological well-being?

\subsection{The Sub-Problems of the Study}

1. Is there a correlation between psychological well-being, unconditional self-acceptance and perfectionistic cognitions in prospective teachers?

2. Do the psychological well-being levels of prospective teachers differ in terms of gender?

3. Do the psychological well-being levels of prospective teachers differ in terms of perceived income level?

\section{Method}

\subsection{Research Model}

This study, which examined the variables that may have a predictive role on the psychological well-being of prospective teachers, was conducted according to the general screening model. The general screening model can be defined as a screening approach conducted on populations composing of a large number of people in order to reach a general idea regarding the population. This model is employed by screening the population as a whole or a certain group or sample within the population (Karasar, 1994).

\subsection{Study Group}

The study group of the current study was composed of 378 prospective teachers studying at the Faculty of Education. Of the study group, $74.3 \%$ were female and $25.7 \%$ were male. Of these prospective teachers, $31.5 \%$ were first graders, $28.8 \%$ were second graders, $20.4 \%$ were third graders and $19.3 \%$ were fourth graders in Faculty of Education. Of these participants, 32.8\% were studying in Preschool Education, 50\% were studying in Special Education and 17.2\% were studying in Turkish Language Teaching. The mean age of the study group was 21.18 years.

\subsection{Data Collection Tools}

In this study data were collected via 'The Psychological Well-Being Scale', 'The Unconditional Self-Acceptance Scale', 'The Perfectionism Cognition Inventory' and 'The Personal Information Form'.

The Psychological Well-Being Scale (PWBS) which developed by Diener et al. (2009) and adapted to Turkish by Telef (2013), consists of eight items. The PWBS which developed to assess multiple aspects of individual functioning ranging from positive relationships to competency feelings, to having purpose and meaning in life, is a seven-Likert scale. The results of the exploratory factor analysis indicated that the total variance explained was $42 \%$ and all items are loaded on a single factor. As a result of the confirmatory factor analysis it was found that the fit indices had acceptable values $(\mathrm{RMSEA}=.08, \mathrm{SRMR}=.04, \mathrm{GFI}=.96, \mathrm{NFI}=.94, \mathrm{RFI}=.92, \mathrm{CFI}=.95$ and $\mathrm{IFI}=.95)$. The Cronbach's alpha coefficient of the scale was calculated as .80. In this study, the Cronbach alpha coefficient for the PWBS was .85.

The Unconditional Self-Acceptance Scale (UCSAS) was developed by Kapıkıran and Kapıkıran (2010) and consists of 19 items. The UCSAS has a two-factor structure and scored with a seven-point Likert scale. The two-factor structure explained $36.77 \%$ of the total variance. To determine the discriminant validity of UCSAS the Dysfunctional Attitudes Scale, the Autonomy Sociothropy Scale and the Brief Symptom Inventory were used and UCSAS was found significantly associated with sociotropy, the Dysfunctional Attitudes Scale and the Brief Symptom Inventory. The Cronbach alpha reliability coefficient of the UCSAS was calculated as .76 while test-re-test correlation was found as .62. The item-total correlations ranged from .40 to .72. In this study, the Cronbach alpha coefficient for the UCSAS was .67.

The Perfectionism Cognition Inventory (PCI) was developed by Flett et al. (1998) and translated and adapted to Turkish culture by Altunbaş (2014). The original form of the PCI has 25 items that adopt five Likert-type scale. In the Turkish version of the scale, a two-factor structure consisting of 21 items was obtained as a result of the exploratory factor analysis. The total variance explained was $44.18 \%$. The results of confirmatory factor analysis for PCI indicated that the two dimensional model was well fit $(\mathrm{x} 2 / \mathrm{sd}=3.51, \mathrm{RMSEA}=.078, \mathrm{SRMR}=.060, \mathrm{CFI}=0.96)$. The Cronbach alpha internal consistency of the PCI was found for self-evaluation according to high standards .90, for negative self-evaluation .76 and for PCI overall .91. In this study, the Cronbach alpha coefficient for the PCI was .72.

The Personal Information Form which was prepared by the researchers was used to collect data on demographic variables of prospective teachers including age, gender, department, class and perceived income level.

\subsection{Data Collection}

The data collection tools were administered to the volunteer prospective teachers studying at the Faculty of Education 
during a regular course hour. Before the administration, all the participants were informed about the purpose of the research and questions of the participants about the research and data collection tools were answered by the researchers during the administration. It took approximately 20 minutes to administer all the data collection tools.

\subsection{Analysis of Data}

First of all, descriptive statistics were calculated for each study variable. Parametric tests were used in statistical analysis due to the number of samples was adequate and the data has a normal distribution. Path analysis was used to examine the predictive roles of unconditional self-acceptance, perfectionistic cognitions and perceived income levels of prospective teachers on their psychological well-being level. In addition, Pearson correlation analysis was performed to determine the relationships between psychological well-being, unconditional self-acceptance, and perfectionistic cognitions of prospective teachers; an independent sample t-test was used to compare mean psychological well-being scores between the male and female groups; and a one-way analysis of variance was applied to compare the mean psychological well-being scores according to perceived income level. The data were analyzed using SPSS 21.0 software and AMOS 22. The significance was tested at .05 level.

\section{Results}

\subsection{Descriptive Statistics}

The mean psychological well-being, unconditional self-acceptance and perfectionistic cognitions scores of the prospective teachers and standard deviations and the correlational associations among study variables were presented in Table 1.

Table 1. Descriptive Statistics For Study Variables and Inter-Correlations of the Variables

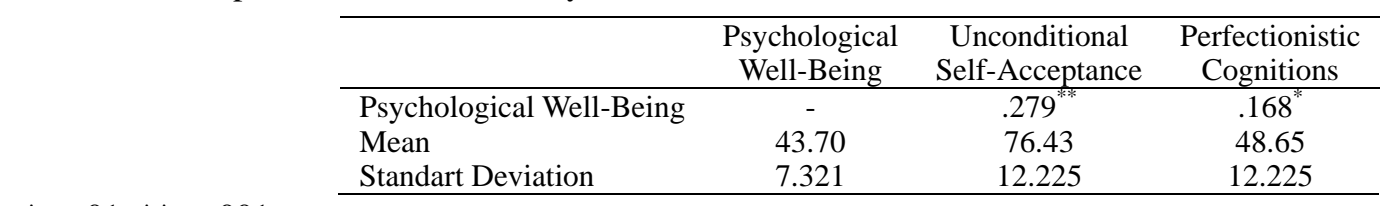

$* \mathrm{p}<.01, * * \mathrm{p}<.001$

As seen in Table 1, the mean psychological well-being scores of prospective teachers was $43.70(\mathrm{Sd}=7.321)$, the mean unconditional self-acceptance scores of participants was $76.43(\mathrm{Sd}=12.225)$ and the mean perfectionist cognitions scores of prospective teachers was 48.65 ( $\mathrm{Sd}=10.577)$. There was a significant, positive but low correlation was found between psychological well-being and unconditional self-acceptance $(\mathrm{r}=.279, \mathrm{p}<.001)$. Similarly, a significant, positive but low correlation was found between psychological well-being and perfectionist cognitions $(r=.168, \mathrm{p}<.01)$.

\subsection{Results of Path Analysis}

A model was established in accordance with previous literature on psychological well-being. The direct and indirect effects of variables were acquired by a path analysis and model fit indices were examined. In comparison to regression analysis, structural equation modeling provides a systematic and comprehensive analysis of a complex research problem in a single process by modeling the relationships between many dependent and independent variables. In addition, the amount of errors resulting from the measurement is minimized in path analysis (Yener, 2007). The standardized coefficients of the paths in the model are shown in Figure 1.

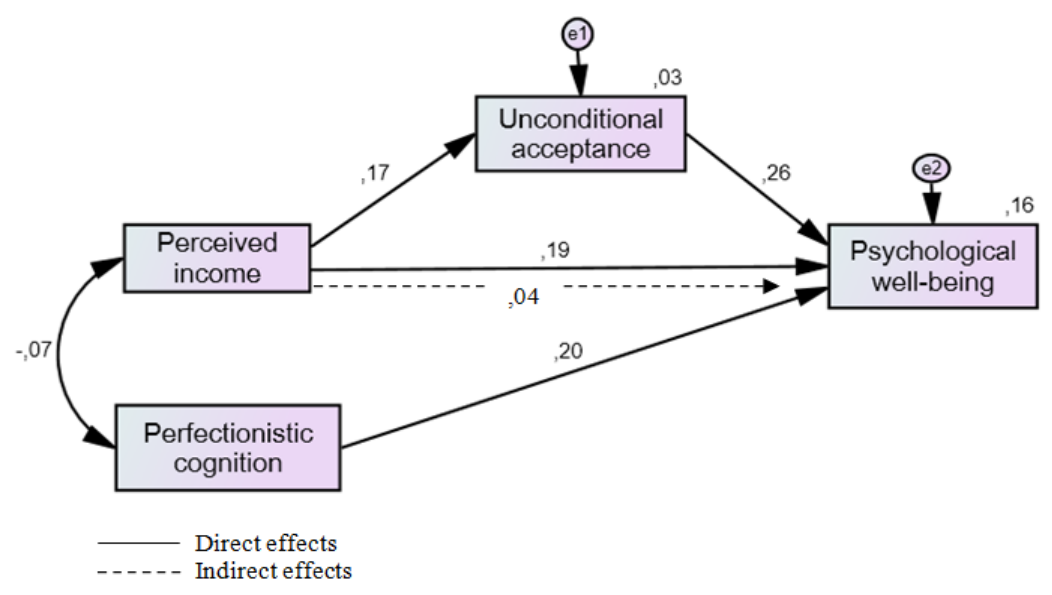

Figure 1. The standardized coefficients of the paths in the model 
According to the results of path analysis, the standardized direct effect of the perceived income level on unconditional self-acceptance and psychological well being were $.17(\mathrm{p}<.001)$ and $.19(\mathrm{p}<.001)$ respectively. The standardized indirect effect of perceived income on psychological well-being was .04. The standardized direct effect of unconditional acceptance and perfectionistic cognitions on psychological well-being were .26 ( $p<.001)$ and .20 (p<.001) respectively.

Moreover, the perceived income level accounted for $3 \%$ of unconditional self-acceptance. The perceived income level, perfectionistic cognitions, and unconditional self-acceptance accounted for $16 \%$ of psychological well-being. Results also indicated that unconditional self-acceptance has the highest impact on psychological well-being and contributes most in the psychological well-being, followed by perfectionistic cognitions, whereas perceived income level is a minor factor. In addition, fit indices of the model was found at an satisfactory level $\left(\mathrm{x}^{2} / \mathrm{df}=1.413, \mathrm{p}=.243\right.$, RMSEA=.033; $\mathrm{GFI}=.997 ; \mathrm{AGFI}=.978 ; \mathrm{NFI}=.968 ; \mathrm{CFI}=.990$ ).

\subsection{Results of Variance Analysis and T-Test}

The results of the independent sample t-test which was performed for comparing the mean psychological well-being scores of prospective teachers in terms of gender were presented in Table 2.

Table 2. Independent Sample T-Test Results of Psychological Well-Being by Gender

\begin{tabular}{|c|c|c|c|c|c|c|}
\hline Gender & $\mathrm{n}$ & Mean & $\mathrm{Sd}$ & df & $\mathrm{t}$ & $\mathrm{p}$ \\
\hline Female & 281 & 44.37 & 6.960 & 376 & 3.045 & $.002 *$ \\
\hline Male & 97 & 41.77 & 8.008 & & & \\
\hline
\end{tabular}
$* \mathrm{p}<.01$

As seen in Table 2, there was a statistically significant difference between mean psychological well-being scores of female prospective teachers and males' $[\mathrm{t}(376)=3.045 ; \mathrm{p}<.01]$. In other words, psychological well-being levels of female prospective teachers $(44.37, \mathrm{Sd}=6.960)$ were higher than males' $(41.77, \mathrm{Sd}=8.008)$.

The results of the One-Way ANOVA which was conducted to determine the differences of mean psychological well-being scores of prospective teachers in relation to perceived income level were presented in Table 3.

Table 3. One Way ANOVA Results of the Psychological Well-Being by Perceived Income Level

\begin{tabular}{llccccc}
\hline Variable & Variance Source & Sum of Square & df & Mean Square & F & p \\
\hline Perceived & Between Groups & 1079.990 & 2 & 539.995 & 10.586 & $.000^{*}$ \\
Income Level & Within Groups & 19128.825 & 375 & 51.010 & & \\
& Total & 20208.815 & 377 & & & \\
\hline
\end{tabular}

$* \mathrm{p}<.001$

According to the results of one-way ANOVA, the mean psychological well-being scores of prospective teachers differ significantly according to perceived income level $[\mathrm{F}(2,375)=10,586 ; \mathrm{p}<.001]$. Bonferroni test as a post hoc test was used to test differences between groups. The Bonferroni test is used in groups where the number of samples is not equal and the groups are homogeneous (Kayri, 2009). The results of the homogeneity of variance test indicated that the mean psychological well-being scores of groups did not differ significantly according to perceived income level ( $p>.05)$. In other words, results suggested that the groups were homogeneous. Bonferroni test was performed due to the number of samples is not equal and the groups are homogeneous, and results of Bonferroni test were presented in Table 4 .

Table 4. Bonferroni Test Results of Mean Differences

\begin{tabular}{lccc}
\hline Perceived Income & Low & Medium & Good \\
\hline Low & - & -1.085 & $-4.856^{*}$ \\
\hline Medium & & - & $-3.772^{*}$ \\
\hline Good & & & - \\
\hline Mean & 41.75 & 42.83 & 46.61 \\
\hline Standart Deviation & 7.708 & 7.492 & 5.890 \\
\hline
\end{tabular}

$* \mathrm{p}<.05$

As seen in Table 4, statically significant differences were observed in means of psychological well-being scrores of prospective teachers in relation to perceived income level. According to these results, psychological well-being levels of prospective teachers who perceived their income level as good $(\bar{X}=46.61)$ were higher than those who perceived their income level as medium $(\bar{X}=42.83)$ and low $(\bar{X}=41.75)$.

\section{Discussion}

According to the results of the research, unconditional self-acceptance and perfectionistic cognitions positively contribute to psychological well-being but their predicting power is small. In addition, it was found that unconditional acceptance, perfectionistic cognitions, and perceived income level accounted for $16 \%$ of psychological well-being. Moreover, it was seen that female prospective teachers' psychological well-being levels were higher than males' and 
participants who perceived their income level as good tended to have higher psychological well-being scores than those who perceived their income level as medium and low.

When the previous literature examined, it is seen that although there are some studies that how that level of psychological wellbeing did not differ significantly by gender (Çelik, 2016; Güler-Edwards, 2008; Saleem \& Saleem, 2017) some other studies suggest that psychological well-being differed by gender. In his study which aims to focus on the meaning of psychological well-being Ryff (1989a) examined the dimensions of psychological well-being by age and gender. He demonstrated that female participants reported a high level of psychological well-being than male participants. Chow (2007) reported that female students had higher levels of psychological well-being. In their study which was conducted to investigate the impact of volunteering in a church on psychological well-being, Krause and Rainville (2018) demonstrated that women volunteers experience a greater sense of well-being than man volunteers. These findings support the results of the present study.

Another finding of this study indicated that psychological well-being levels of participants who perceived their income level as good were higher than those who perceived their income level as medium and low. There are many studies that support this finding (Cenkseven, 2004; Chow, 2007; Krause \& Rainville, 2018; Mills et al., 1992; Moe, 2012). Economic difficulties may reduce psychological well-being in men and women working full time (Mills et al., 1992) and as the socioeconomic status increased the psychological well-being also increased (Cenkseven, 2004; Krause \& Rainville, 2018). Chow (2007) demonstrated that participants who had a higher family income and a better physical health, stated a greater level of satisfaction with their relationships with family, friends, and others, displayed a more positive self-image and had less academic stress tended to exhibit a higher level of psychological well-being. In his research Moe (2012), considered economic income instead of perceived income, and found that psychological well-being increased as perceived income increased. These researches support our research findings.

In our review of the previous literature, no study was found which addressed the predictive roles of unconditional self-acceptance, perfectionistic cognitions and perceived income level together. To our knowledge, only Godin (2010) investigated the relationship between psychological well-being, knowledge of the Enneagram system and unconditional self-acceptance. As a result, she concluded that there was no association between psychological well-being and knowledge of the Enneagram system but there was a low positive correlation between psychological well-being and unconditional self-acceptance. These results are consistent with our results indicating that there is a positive bot low association between psychological well-being and unconditional self-acceptance. Indeed, it is thought that self-acceptance which is a dimension of psychological well-being (Ryff, 1989a) is necessary for mental health (Rogers, 1951). Therefore, it is not surprising that self-acceptance and psychological well-being are related.

There are several studies in the literature on predictors of psychological well-being. In these studies, the predictor roles of religiosity (Saleem \& Saleem, 2017), past experiences (Ryff \& Heidrick, 1997), perceived social support (Garcia, Ramirez, Jariego, \& Isidro, 2002; Moe, 2012; VanderZee, Buunk, \& Sonderman,1997), individual control (Garcia et al. , 2002), education and income level (Moe, 2012) on psychological well-being were examined. In their study, Cenkseven and Akbaş (2007) found that subjective well-being and psychological well-being of university students were predicted by extraversion, neuroticism, the locus of control, learned resourcefulness, social relations, leisure activities, and gender. Baroni, Nerini, Matera and Stefanile (2016) demonstrated that psychological well-being has an important role in mediating the relationship between emotional distress and mindfulness. No study was found which addresses the role of perfectionistic cognitions on psychological well-being. The results of the current study suggested that perfectionistic cognitions positively contribute to psychological well-being, but its contribution to the variance is small. In the previous literature on perfectionistic cognitions, it is surprising that psychological well-being increases as perfectionist cognitions increases. People who often use perfectionist cognitions often criticize and punish themselves (Flett et al., 1998) thus this may adversely affect their psychological well-being. Indeed, perfectionistic cognitions is known to be associated with high stress and anxiety (Flett et al., 2002). However, in Ryff's (1995) theory, it is emphasized that an individual should realize his/her true potential and expand his/her potential to strive for perfection. In addition, perfectionism has a positive and healthy component. Given that the positive and healthy component of perfectionism which is labeled as perfectionistic strivings were associated with conscientiousness, positive emotions and life satisfaction (Stoeber \& Otto, 2006)' it can be expected to have an impact on psychological well-being. Besides, an individual with high psychological well-being is aware of the histher potential and strives (Keyes et al., 2002). It can be said that striving self-development is also related to perfectionist effort.

Psychological well-being of teachers who play a critical role in children's development seems to be important. Therefore, it can be suggested to develop intervention programs to increase the psychological well-being level of teachers and teacher candidates. In this respect, it is necessary to take into account the variables predicting psychological well-being. By improving the unconditional self-acceptance skills and perfectionist efforts of individuals, the level of psychological well-being can be increased indirectly. Further studies can be carried out not only with prospective teachers but also with teachers working in schools. The variables predicting psychological well-being can be investigated in different and larger sample groups. 


\section{References}

Akın, A. (2009). The effect of rational emotive behavioral therapy based group counseling to the psychological well-being and self-compassion (Unpublished doctoral thesis), Sakarya University, Social Sciences Institute, Sakarya.

Altunbaş, G. (2014). Psychoeducation program on the use of university students' cognitive emotion regulation strategy and its effect on cognition perfectionists. (Unpublished doctoral thesis), Gazi University, Education Sciences Institute, Ankara.

Baroni, D., Nerini, A., Matera, C., \& Stefanile, C. (2016). Mindfulness and emotional distress: the mediating role of psychological well-being. Curr Psychol, 37, 467-476. https://doi.org/10.1007/s12144-016-9524-1

Besser, A., Flett, G., \& Hewitt, P. L. (2010). Perfectionistic self-presentation and trait perfectionism in social problem-solving ability and depressive symptoms. Journal of Applied Social Psychology, 40, 2121-2154. https://doi.org/10.1111/j.1559-1816.2010.00653.x

Bradburn, N. M. (1969). The structure of psychological well-being. Chicago: Aldine.

Çelik, O. (2016). Investigating psychological well-being, perceived social competence and assertiveness in pre-service teachers (Unpublished master's thesis). Erzincan University, Social Sciences Institue, Erzincan.

Cenkseven, F. (2004). Examining the predictors of subjective and psychological well-being of university students (Unpublished doctoral thesis), Çukurova University, Social Sciences Institute, Adana.

Cenkseven, F., \& Akbaş, T. (2007). Examining the predictors of subjective and psychological well-being of university students. Turkish Psychological Counseling and Guidance Journal, 3, 43-65.

Chow, H. P. (2007). Psychological well-being and scholastic achievement among university students in a Canadian Prairie City. Soc Psychol Educ, 10, 483-493. https://doi.org/10.1007/s11218-007-9026-y

Diener, E., Wirtz, D., Biswas-Diener, R., Tov, W., Kim-Prieto, C., Choi, D., et al. (2009). New measures of wellbeing. Social Indicators Research Series book series (SINS, 39). The Netherlands: Springer. https://doi.org/10.1007/978-90-481-2354-4

Dryden, W., David, D., \& Ellis, A. (2010). Rational emotive behavior therapy. In Dobson, K. S. (Ed.), Handbook of cognitive behavioral therapies (pp. 226-276). Newyork, USA: The Guilford Press.

Ellis, A. (1977). Psychotherapy and the value of a human being. In A. Ellis \& R. Grieger (Eds.), Handbook of rational-emotive therapy. New York, USA: Springer.

English, H. B., \& English, A. C. (1958). A comprehensive dictionary of psychological and psychoanalytical terms. New York, USA: Longmans.

Flett, G. L., Hewitt, P. L., Blankstein, K. R., \& Gray, L. (1998). Psycological distress and the frequency of perfectionistic thinking. Journal of Personality and Social Psychology, 75, 1363-1381. https://doi.org/10.1037/0022-3514.75.5.1363

Flett, G. L., Madorsky, D., Hewitt, P. L., \& Heisel, M. J. (2002). Perfectionism cognitions. rumination and psychological distress. Journal of Rational-Emotive and CognitiveBehavior Therapy, 20, 33-47. https://doi.org/10.1023/A:1015128904007

Garcia, M. F., Ramirez, M., \& Jariego, I. M. (2002). Social support and locus of control as predictors of psychological well-being in moroccan and peruvian immigrant women in spain. International Journal of Intercultural Relations, 26, 287-310. https://doi.org/10.1016/S0147-1767(02)00005-6

Godin, J. (2010). The effect of the enneagram on psychological well-being and unconditional self-acceptance of young adults (Doctor of philosophy). Family and Consumer Sciences Education, Iowa State University.

Güler-Edwards, A. (2008). Relationship between future time orientation, adaptive self-regulation, and well-being: self-type and age related difference (PhD Thesis). The Graduate School of Social Sciences Of Middle East Technical University.

Hewitt, P. L., \& Flett, G. L. (2002). Perfectionism and stress proceses in psychopathology. In G. L. Flett \& P. L. Hewitt (Eds.). Perfectionism: Theory, research and treatment (pp. 255-284). Washington. D.C.: American Psychological Association. https://doi.org/10.1037/10458-011

Hewitt, P. L., \& Flett, G. L. (2007). When does conscientiousness become perfectionism? Current Psychiatry, 6, 49-60.

Hill, A. P., Hall, H. K., Appleton, P. R., \& Kozub, S. A. (2008). Perfectionism and burnout in junior elite soccer players: 
The mediating influence of unconditional self-acceptance. Psychology of Sport and Exercise, 9, 630-644. https://doi.org/10.1016/j.psychsport.2007.09.004

Jersild, A. T. (1960). Child psychology. New Jersey, USA: Prentice-Hall.

Kahn, J. H., Hessling, R. M., \& Russell, D. W. (2003). Social support, health, and wellbeing among the elderly: What is the role of negative affectivity? Personality and Individual Differences, 3, 5-17. https://doi.org/10.1016/S0191-8869(02)00135-6

Kapıkıran, S., \& Kapıkıran, N. A. (2010). The validity and reliability of the perceived available support scale. Ankara University Journal of Faculty of Educational Sciences, 43, 51-74. https://doi.org/10.1501/Egifak_0000001202

Karademas, E. C. (2006). Self-Efficacy, social support and well-being the mediating role of optimism. Personality and Individual Differences, 40(6), 1281-1290. https://doi.org/10.1016/j.paid.2005.10.019

Karasar, N. (1994). Scientific research method. Ankara: 3 A Araştırma Danışmanlık Limited.

Kayri, M. (2009). The multiple comparison (post-hoc) techniques to determine the difference between groups in researches. Firat University Journal of Social Sciences, 19, 51-64.

Keyes, C. L. M., Shmotkin, D., \& Ryff, C. D. (2002). Optimizing well being: the emprical encounter of two traditions. Journal of Personality \& Social Psychology, 82, 1007-1023. https://doi.org/10.1037/0022-3514.82.6.1007

Krause, N., \& Rainville, G. (2018). Volunteering and psychological well-being: Assessing variations by gender and social context. Pastoral Psychol, 67, 43-53. https://doi.org/10.1007/s11089-017-0792-y

Lavasani, M. G., Borhanzadeh, S., Afzali, L., \& Hejazi, E. (2011). The relationship between perceived parenting styles, social support with psychological well- being. Procedia Social and Behavioral Sciences, 15, 1852-1856. https://doi.org/10.1016/j.sbspro.2011.04.014

MacInnes, D. (2003). Evaluating an assessment scale of irrational beliefs for people with mental health problems. Nurse researcher, 10(4), 53-67. https://doi.org/10.7748/nr2003.07.10.4.53.c5907

Maier, E. H., \& Lachman, M. E. (2000). Consequences of early parental loss and separation for health and well-being in midlife. International Journal of Behavioral Development, 24, 183-189. https://doi.org/10.1080/016502500383304

Mills, R. J., Grasmick, H. G., Morgan, C. S., \& Wenk, D. (1992). The effects of gender, family satisfaction and economic strain on psychological well-being. Family Relations, 41, 440-446. https://doi.org/10.2307/585588

Moe, K. (2012). Factors influencing women's psychological well-being within a positive functioning framework (Doctor of Philosophy). College of Education, University of Kentucky.

Neenan, M. M., \& Dryden, W. (2005). Rational emotive behaviour therapy in a nutshell. https://0-ebookcetral-proquest-com.seyhan.library.boun.edu.tr/lib/bogazici-ebooks/detail. action?docID=334511

Rogers, C. D. (1951). Client-centered therapy. Boston: Houghton Mifflin.

Roothman, B., Kirsten, D. K., \& Wissing, M. P. (2003). Gender differences in aspects of psychological well-being. South African Journal of Psychology, 33, 212-218. https://doi.org/10.1177/008124630303300403

Ryff, C. D. (1989a). Happiness is everything, or is it? Explorations on the meaning of psychological well-being. Journal of Personality and Social Psychology, 57, 1069-1081. https://doi.org/10.1037/0022-3514.57.6.1069

Ryff, C. D. (1989b). Beyond ponce de leon and life satisfaction: New directions in quest of successful ageing. International Journal of Behavioral Development, 12, 33-55. https://doi.org/10.1177/016502548901200102

Ryff, C. D. (1995). Psychological well-being in adult life. Current Directions in Psychological Science, 4, 99-104. https://doi.org/10.1111/1467-8721.ep10772395

Ryff, C. D., \& Heidrich, S. M. (1997). Experience and well-being: explorations on domains of life and how they matte. International Journal Of Behavioral Development, 20, 193-206. https://doi.org/10.1080/016502597385289

Ryff, C. D., \& Singer, B. H. (2008). Know thyself and become what you are: A eudaimonic approach to psychological well-being. Journal of Happiness Studies, 9(1), 13-39. https://doi.org/10.1007/s10902-006-9019-0

Ryff, C. D., Magee, W. J., Kling, K. C., \& Wing, E. H. (1999). Forging macro-micro linkages in the study of psychological well-being. In C.D. Ryff \& V. W. Marshall (Eds.), The self and society in aging processes (pp.247-278). New York, USA: Springer.

Saleem, S., \& Saleem, T. (2017). Role of religiosity in psychological well-being among medical and non-medical students. J Relig Health, 56, 1180-1190. https://doi.org/10.1007/s10943-016-0341-5 
Schmutte, P. S., \& Ryff, C. D. (1997). Personality and well-being: reexamining methods and meanings, Journal of Personality and Social Psychology, 73, 549-559. https://doi.org/10.1037/0022-3514.73.3.549

Scott, W. A. (1968). Conceptions of normality. In E. F. Borgatta \& W. W. Lambert (Eds.), Handbook of personality theory and research. New York, USA: Rand McNally.

Segrin, C., \& Taylor, M. (2007). Positive interpersonal relationships mediate the association between social skills and psychological well-being. Personality and Individual Differences, 43, 637-646. https://doi.org/10.1016/j.paid.2007.01.017

Shakespeare-Finch, J. E., \& Green, J. (2013). Social support promotes psychological well-being following a natural disaster. In Australia and New Zealand Disaster and Emergency Management Conference. AST Management Pty Ltd, Mercure Hotel, Brisbane, QLD, 210-229.

Stoeber, J., \& Otto, K. (2006). Positive conceptions of perfectionism: Approaches. evidence. challenges. Personality and Social Psychology Review, 10, 295-319. https://doi.org/10.1207/s15327957pspr1004_2

Telef, B. B. (2013). The adaptation of psychological well-being into Turkish: A validity and reliability study. Hacettepe University Journal of Education, 28, 374-384.

Vanderzee, K. I., Buunk, B. P., \& Sanderman, R. (1997). Social support, locus of control, and psychological well-being. Journal of Applied Social Psychology, 27(20), 1842-1859. https://doi.org/10.1111/j.1559-1816.1997.tb01628.x

Waterman, A. S. (1993). Two conceptions of happiness: Contrasts of personal expressiveness (eudaimonia) and hedonic enjoyment. Journal of Personality and Social Psychology, 64, 678-69. https://doi.org/10.1037/0022-3514.64.4.678

Yener, H. (2007). Personel performansina etki eden faktörlerin yapısal eşitlik modeli (YEM) ile incelenmesi ve bir uygulama (Unpublished doctoral thesis). Gazi University, Institute of Science, Ankara.

\section{Copyrights}

Copyright for this article is retained by the author(s), with first publication rights granted to the journal.

This is an open-access article distributed under the terms and conditions of the Creative Commons Attribution license which permits unrestricted use, distribution, and reproduction in any medium, provided the original work is properly cited. 